Article

\title{
Practice Framework for the Management of Post-Disaster Housing Reconstruction Programmes
}

\author{
Abdulquadri Ade Bilau *, Emlyn Witt(1) and Irene Lill(1) \\ Department of Civil Engineering and Architecture, Tallinn University of Technology, Ehitajate tee 5, \\ 19086 Tallinn, Estonia; emlyn.witt@taltech.ee (E.W.); irene.lill@taltech.ee (I.L.) \\ * Correspondence: abdulquadri.bilau@taltech.ee
}

Received: 26 September 2018; Accepted: 25 October 2018; Published: 29 October 2018

check for updates

\begin{abstract}
Despite an international consensus for housing to be "built back better" (BBB) following disasters, and the considerable resources expended on reconstruction efforts globally, the management of post-disaster housing reconstruction programmes often leaves much to be desired. This research presents a framework for the management of post-disaster housing reconstruction in developing countries based on a comprehensive identification of the issues affecting the management of reconstruction programmes and the management measures which have proved effective in mitigating these issues and achieving the desired BBB outcomes. The framework highlights the strategic importance of preparedness measures that should be taken before the next disaster strikes and the cross-cutting nature of capacity building and beneficiary community engagement measures that are essential to all stages of the post-disaster reconstruction process. The research findings are limited to developing countries, as the evidence on which they are based is almost entirely from post-disaster housing experiences in the developing world. The framework may, however, be adapted to different, specific post-disaster reconstruction contexts. This research has compiled, extended and up-dated current knowledge regarding the management of housing reconstruction programmes and it provides practical guidance for policy makers and practitioners.
\end{abstract}

Keywords: developing countries; disaster resilience; housing reconstruction; natural hazards; reconstruction management

\section{Introduction}

Disasters damage the built environment. The extensive destruction of houses and infrastructure is accompanied by fatalities and injuries, loss of livelihood sources and the stagnation or reversal of local economies [1]. Housing is the most valuable social and economic asset [2,3] and is an essential loss component in disasters, particularly in developing countries [4-7], where affected communities become susceptible to homelessness and severe humanitarian conditions.

Housing is particularly affected by disasters [8] and, coupled with its centrality to humanitarian and international development concerns $[9,10]$, substantial resources from multiple sources are channelled to post-disaster reconstruction [7] with a significant portion of these allocated to permanent housing reconstruction (PHR). Apart from being a visible investment choice, PHR is an effective means to provide safety and security, and to restore dignity and better livelihood conditions to mitigate the suffering of affected and/or displaced communities [11-14]. It typically follows the provision of emergency shelter, temporary shelter and temporary and transitional housing $[15,16]$. Post-disaster housing reconstruction extends beyond the traditional replacement of damaged or destroyed housing stock to produce dwellings [11,17]. It is a significant process fraught with complexities, challenges and uncertainties that requires an integrated plan and a coordinated chain of activities and stakeholders [5,18-20] in order to facilitate the quick production of safe, liveable and 
acceptable disaster resilient housing and community recovery [21-23] in the chaotic, dynamic and complex reconstruction environment [24-26].

As a process, PHR is required to facilitate "build back better" (BBB) through the reduction of underlying disaster risk factors, building and strengthening local capacities for resilient development, enabling social and economic recovery of affected communities at all levels, and supporting the long-term sustainability of the PHR outcomes [13,27-29]. These outcomes include: technical aspects-local capacity to ensure resilient development, and maintenance of existing structures [30]; social aspects—sustenance of values (including culture and belief), and networks that enable social progress [31,32]; economic aspects-sustained livelihood provision and local economic growth; and, environmental aspects-effective protection and sustainability of the reconstructed settlement and environment [31]. Long-term sustainability of PHR programmes also relates to institutional aspects that enable the provision of effective and continuous assistance or support (information, education, technical assistance, etc.) [10,33], and should be sustained following reconstruction for over 10 years [32,34], in line with the expectations of the Sendai Framework for Disaster Risk Reduction 2015-2030 [35].

Housing evaluation reports $[36,37]$ and studies $[7,38]$ have identified PHR as ineffective and one of the least successful humanitarian sectoral interventions. This has led to calls for appropriate measures and strategies to guide policy-makers and practitioners towards achieving effective PHR programmes [38]. In this regard, a few studies [32,39,40] have proposed models or frameworks for post-disaster reconstruction to enhance community resilience to disasters. Specifically, [39] conceived a housing reconstruction model for community involvement in post-disaster housing recovery processes based on experiences from Turkey. Ref. [32] proposed a framework for owner-driven housing reconstruction projects to enhance disaster resilience in the long-term and at a micro-scale, and [40] developed a framework for effective disaster resettlement through community participation. These frameworks do not, however, provide comprehensive processes for the management of large-scale housing reconstruction programmes involving multiple scales. This paper therefore presents a framework for the management of housing reconstruction programmes involving multiple scales to enhance communities' resilience to disasters. The framework is intended to provide guidance to policy makers and managers of PHR programmes.

In carrying out this research, a conceptual framework was first developed (Figure 1) and published in [41], which framed the problem in terms of management issues arising from the post-disaster context, management measures (initially referred to as management strategy elements) to mitigate the issues and the desired outcome goals of the housing reconstruction process.

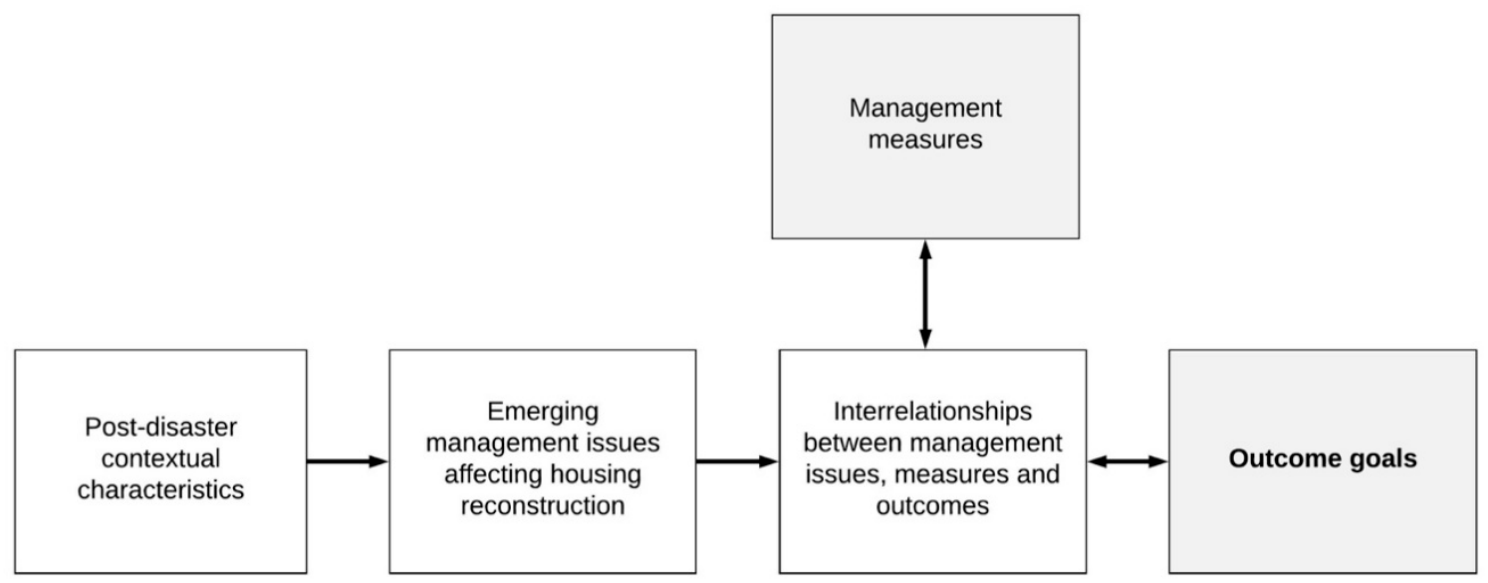

Figure 1. Conceptual framework for the management of post-disaster housing reconstruction.

In this paper, the research methodology is first described (Section 2), followed by the findings in terms of the desired outcome goals of housing reconstruction (Section 3), and the issues that affect 
the management of PHR (Section 4). Section 5 describes the management measures which were identified and how these have been integrated and organised in order to provide a usable framework for managing post-disaster housing reconstruction. The framework itself is then presented and conclusions are drawn.

\section{Research Methodology}

This study was conducted in the context of $\mathrm{PhD}$ research, and adopted a qualitative research approach following the process stages illustrated in Figure 2.

The literature review process commenced with a review of the historical case studies to identify the successes and failures of past PHR programmes and to understand the management challenges facing them. This case-study review enabled an initial identification of the management issues affecting PHR effectiveness [42]. Drawing on this, a systematic search and comprehensive review of the literature were then carried out to identify the characteristics of the PHR context, the management issues that arise, the management approaches applied and the expected outcome goals for housing reconstruction initiatives. On the basis of the findings, a conceptual framework for PHR management was proposed [41]. The conceptual framework provided a basis for an "evidence-focused" review of the academic and grey literature to draw out effective measures for resolving the issues affecting the management of post-disaster housing reconstruction programmes. The measures drawn in relation to the outcome expectations of PHR interventions were thematically analysed, synthesised and presented [43].

\section{PROCESS}

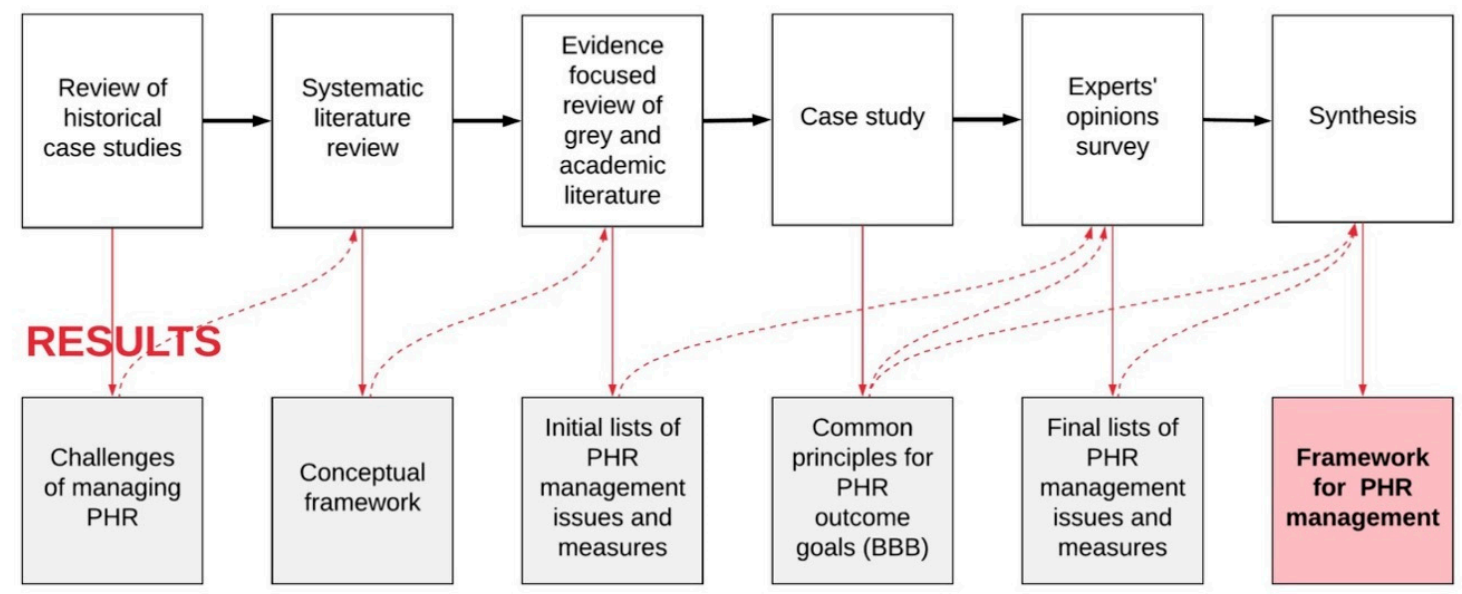

Figure 2. Research process for the development of framework for the management of PHR programmes.

An exploratory case study of the housing reconstruction and recovery programme in Lokoja, Kogi State, Nigeria, was undertaken with 31 semi-structured interviews of stakeholders conducted. The questionnaire guide was designed drawing on the "Build Back Better" (BBB) expectations under the Sendai Framework for Disaster Risk Reduction 2015-2030 (SFDRR) and utilising the BBB framework [27] to determine the issues affecting PHR, measures applied in managing the issues and whether the reconstruction programme measured up to stakeholders' outcome expectations. Data collected were coded and thematically analysed [44].

A final phase of data collection involved in-depth, semi-structured interviews (of between 60-90 $\mathrm{min}$ ) conducted with 17 experts in the field of study. (Table 1 shows the profiles of the interviewees.) Expert interviewees were identified through a purposive-snowballing technique, experts' recommendations and their ability to provide information and/or opinions on PHR programmes. Experts were drawn from different geographical locations with wide-ranging experience in developing countries, including Bangladesh, Haiti, India, Indonesia, Iran, Maldives, Malaysia, 
Nepal, Pakistan and Sri Lanka, working with multi-lateral donor agencies, reconstruction management agencies, international non-government organisations (INGOs) and higher education institutions (HEIs) as policy-makers, practitioners and researchers [45]. Expert interviews were conducted to fill gaps in the data obtained from secondary sources, to minimise bias, triangulate the data collection sources and methods, and to increase the validity and reliability of the research findings [46].

Table 1. Interview respondents' profiles.

\begin{tabular}{|c|c|c|c|c|}
\hline Int. Code & Experience & Designation & Organisation & Experience Country Example \\
\hline I\#1 & $>10$ & Programme manager & UN Agency & India, Maldives, Sri Lanka \\
\hline I\#2 & $>15$ & Project mgt. expert PHR & Donor org., INGO & India, Nepal, Sri Lanka \\
\hline I\#3 & $>20$ & Programme director & Reconst. authority & Pakistan \\
\hline I\#4 & $>30$ & Reconstruction expert & UN agency & Pakistan, Sri Lanka \\
\hline I\#5 & $>20$ & Professor Disaster resilience & HEI & Indonesia, Sri Lanka \\
\hline I\#6 & $>20$ & Consultant-Expert & Housing (line) agency & Iran \\
\hline I\#7 & $>25$ & Expert, Development planning & UN agency & Japan, Malaysia, Nepal \\
\hline $\mathrm{I} \# 8$ & $>15$ & Researcher, Disaster mgt. & HEI & Australia, Sri Lanka \\
\hline I\#9 & $>25$ & Expert/Practitioner & $\begin{array}{c}\text { Donor org., INGO, UN } \\
\text { Agency }\end{array}$ & Indonesia, Nepal, Philippines \\
\hline I\#10 & $>10$ & Practitioner/researcher & Donor org., INGO & Indonesia \\
\hline I\#11 & $>15$ & $\begin{array}{l}\text { Specialist, Housing } \\
\text { reconstruction }\end{array}$ & UN agency & $\begin{array}{c}\text { Bangladesh, India, Indonesia, } \\
\text { Nepal }\end{array}$ \\
\hline I\#12 & $>10$ & $\begin{array}{l}\text { Specialist, Coordination and } \\
\text { Communication }\end{array}$ & INGO & Indonesia \\
\hline I\#13 & $>15$ & Head, Technical team & INGO & Sri Lanka \\
\hline I\#14 & $>15$ & Researcher, Disaster resilience & HEI & Sri Lanka, UK \\
\hline I\#15 & $>10$ & Researcher, Disaster resilience & HEI & Sri Lanka, UK \\
\hline I\#16 & $>20$ & $\begin{array}{l}\text { Professor Project Mgt and } \\
\text { Disaster Resilience }\end{array}$ & HEI & Sri Lanka, UK \\
\hline I\#17 & $>10$ & $\begin{array}{l}\text { Expert/Researcher, Disaster } \\
\text { Resilience }\end{array}$ & HEI & Indonesia, Malaysia, UK \\
\hline
\end{tabular}

Information obtained from the interviews was transcribed, coded and categorised under pre-identified and emerging themes using NVivo 11. The results obtained were synthesised with those from the preceding evidence-focused review and the case-study to validate the pre-identified issues and to identify the measures for managing PHR programmes in developing countries. Subsequent integration and organisation of the measures with respect to time resulted in the development of a framework for the management of PHR programmes.

\section{Outcome Expectations for Post-Disaster Housing Interventions}

Whereas studies [11,41] have identified that large-scale PHR programmes have various objectives due to the interests of the multitude of stakeholders involved (e.g., risk reduction, reestablishment of permanent community, quick reconstruction of acceptable housing and socio-economic recovery of communities, and sustainability of reconstruction projects), the Sendai Framework for Disaster Risk Reduction 2015-2030 (SFDRR) identifies the need to utilise the PHR window as an opportunity to enhance preparedness for effective response and to "Build Back Better" (BBB) [35]. As a priority area for action, BBB advocates the effective implementation of reconstruction processes to enable systematic integration of risk reduction measures and to facilitate the recovery of affected communities in order to strengthen the communities' resilience to disasters $[7,27,28,47]$. Thus, the overall outcome goals for any PHR programme, as agreed by global stakeholders, are to reduce disaster risk and to facilitate social and economic recovery of communities through effective implementation of the reconstruction process. See $[27,48]$. 


\subsection{Disaster Risk Reduction}

Disaster risk reduction (DRR) concerns the methodical identification, analysis and prevention of new risk, reduction of existing disaster risk and management of residual risk to strengthen disaster resilience [49]. DRR comprises measures to minimize socio-economic vulnerabilities and environmental hazards, and to improve the capacity and resilience of communities [33,49]. Risk reduction involves establishing and integrating structural and non-structural measures into the reconstruction process $[13,50]$. Structural measures include improved design and building codes, strengthening of vulnerable structures and implementation of effective construction practices [50,51]. Non-structural risk reduction measures include vulnerability analyses and effective land management through hazard-based land use planning, legislative, regulatory and policy provision to minimise disaster risk and impacts, training and capacity building, sensitisation and public enlightenment campaigns $[49,50]$. The integration of risk reduction measures into reconstruction lessens vulnerabilities and enhances the resilience of structures and communities in order to mitigate exposure to hazards, reduce disaster risk and bring about safer communities [27,50,52-54].

\subsection{Community Recovery}

With the loss of loved ones and family networks, damage to properties and livelihood sources, and impacts on local economies [1], communities become susceptible to traumatic stress and harsh economic conditions leading to increased mortality and psychosocial issues [55,56]. Mannakkara and Wilkinson have considered community recovery in terms of social and economic recovery [27].

\subsubsection{Social Recovery}

The social recovery of communities is enabled through community consultation, participation and involvement in the PHR design and construction processes, allowing positive beneficiary input and alignment with beneficiaries' needs [57-59]. This helps to reduce trauma and hopelessness, and fosters the re-establishment of social networks while strengthening coping capabilities $[60,61]$. Beneficiary community engagement enhances the sense of ownership, restores dignity and improves confidence in the safety and quality of the new buildings [14,62,63]. A lack of community participation in PHR programmes goes against the principles of the SFDRR and denies the affected community an opportunity for recovery [44].

\subsubsection{Economic Recovery}

Active participation of beneficiaries in the PHR process requires the provision of training and capacity building which provide beneficiaries with new skills and alternative livelihood sources. Employment opportunities for beneficiaries within the PHR programme also contribute to the programme's long-term sustainability as housing is more likely to be properly maintained $[25,27]$. The engagement of local businesses in logistics and supply functions during the reconstruction process contributes to the revival of local markets, facilitates the return of businesses, and improves social and economic conditions for the affected communities [27].

\section{Issues Affecting the Management of Post-Disaster Housing Reconstruction}

Numerous issues arise in the post-disaster context which make the management of PHR programmes particularly challenging $[19,21,25,41,64-66]$. The ineffective management of these issues leads to the failure of PHR interventions to achieve their intended outcomes. Table 2 summarises the issues identified in this research, firstly from the literature, and the expert interviews. The issues are organised into categories and, within each category, they are ranked according to the number of experts referring to them in the experts' opinion survey. Note that issues having the same number of experts referring to them are grouped and synthesised in the same cells. 
Table 2. Issues affecting the management of post-disaster housing reconstruction.

\begin{tabular}{|c|c|c|}
\hline Issue Category & $\begin{array}{l}\text { Issues Affecting Post-Disaster Housing Reconstruction } \\
\text { Effectiveness }\end{array}$ & $\begin{array}{l}\text { No. of } \\
\text { Sources }\end{array}$ \\
\hline \multirow{4}{*}{$\begin{array}{l}\text { Coordination and } \\
\text { communication }\end{array}$} & Inadequate or unfair distribution of resources, roles and responsibilities. & 4 \\
\hline & $\begin{array}{l}\text { Ineffective communication between stakeholders (including lack of } \\
\text { communication tools, communication gaps, lack of } \\
\text { stakeholder cooperation). }\end{array}$ & 3 \\
\hline & $\begin{array}{l}\text { Inadequate local institutional capacity associated with poor } \\
\text { coordination of stakeholders and lack of trust among } \\
\text { implementing parties. }\end{array}$ & 2 \\
\hline & $\begin{array}{l}\text { Unclear delineation of implementing responsibilities leading to gaps, } \\
\text { overlaps and duplication of efforts, confusion and wastage of } \\
\text { scarce resources. } \\
\text { Donor agencies' insensitivity to community needs resulting from lack } \\
\text { or inadequate beneficiary participation and engagement leading } \\
\text { to resentment. }\end{array}$ & 1 \\
\hline \multirow{2}{*}{$\begin{array}{l}\text { Financial } \\
\text { management }\end{array}$} & $\begin{array}{l}\text { Donor-pledges delayed or not materialising at all (including due to } \\
\text { corruption and lack of transparency and accountability) and associated } \\
\text { with cash flow constraints. }\end{array}$ & 3 \\
\hline & $\begin{array}{l}\text { Non-flexibility of budgetary systems and stipulated spending deadlines. } \\
\text { Inadequate local institutional capacity to manage and disburse donor } \\
\text { funds, including a lack of or inability to use financial management, } \\
\text { accounting and reporting systems and standards. }\end{array}$ & 2 \\
\hline \multirow{6}{*}{ Human resources } & $\begin{array}{l}\text { Lack or shortage of readily deployable experts, local builders and } \\
\text { skilled workers. }\end{array}$ & 15 \\
\hline & $\begin{array}{l}\text { Escalation of labour wages in the reconstruction environment coupled } \\
\text { with donor or implementing agencies' financial constraints to pay good } \\
\text { wages or salaries affects the ability to engage and/or retain the requisite } \\
\text { skilled workers. }\end{array}$ & 6 \\
\hline & $\begin{array}{l}\text { Inadequate local human resources at the strategic level affects effective } \\
\text { reconstruction policy formulation. }\end{array}$ & 4 \\
\hline & $\begin{array}{l}\text { The need for quick and extensive skilled workforce mobilisation and } \\
\text { recruitment and the high labour turnover resulting from seasonal } \\
\text { influences, competition among agencies, low job satisfaction } \\
\text { and motivation. }\end{array}$ & 3 \\
\hline & $\begin{array}{l}\text { Tensions between local resource capacities and external human } \\
\text { resourcing (political and trade union issues). }\end{array}$ & 2 \\
\hline & $\begin{array}{l}\text { Cultural issues related to acceptability of new (graduate) engineers by } \\
\text { the community, the need for skilled manpower importation and } \\
\text { difficulties faced by invited workers due to visa issues. }\end{array}$ & 1 \\
\hline \multirow[t]{2}{*}{ Health and safety } & $\begin{array}{l}\text { Insufficient awareness of health and safety risks present in the } \\
\text { reconstruction environment, lack of harmonised health and safety } \\
\text { standards and the non-adherence and inadequate enforcement of } \\
\text { building codes (health and safety regulations) and } \\
\text { construction guidelines. }\end{array}$ & 2 \\
\hline & $\begin{array}{l}\text { Reuse of substandard and hazardous (salvage) materials, use of } \\
\text { materials and massive transportation of materials producing unsafe } \\
\text { conditions, cultural and attitude problems and lack of commitment to } \\
\text { health and safety. }\end{array}$ & 1 \\
\hline
\end{tabular}


Table 2. Cont.

\begin{tabular}{|c|c|c|}
\hline Issue Category & $\begin{array}{l}\text { Issues Affecting Post-Disaster Housing Reconstruction } \\
\text { Effectiveness }\end{array}$ & $\begin{array}{l}\text { No. of } \\
\text { Sources }\end{array}$ \\
\hline \multirow{4}{*}{ Logistics and supplies } & $\begin{array}{l}\text { Material price increases and inflation affects resource supplies and } \\
\text { overall reconstruction cost leading to reduced housing provided. }\end{array}$ & 5 \\
\hline & $\begin{array}{l}\text { Delays in procurement processes and resource supplies associated with } \\
\text { the scale of resource needs, high transportation costs and difficult } \\
\text { access to the reconstruction environment resulting from the lack of or } \\
\text { damage to roads, infrastructure and services. }\end{array}$ & 4 \\
\hline & $\begin{array}{l}\text { Material supply shortages associated with the high demand of } \\
\text { materials due to concurrent reconstruction projects and disaster impacts } \\
\text { on local markets. }\end{array}$ & 3 \\
\hline & $\begin{array}{l}\text { Need for importation and difficulty in clearing imported materials, } \\
\text { disrupted and inadequate local supply chains and poor supply quality } \\
\text { (wrong and damaged material delivery). }\end{array}$ & 1 \\
\hline \multirow{5}{*}{$\begin{array}{l}\text { Workmanship } \\
\text { and quality }\end{array}$} & $\begin{array}{l}\text { Inadequate training and mentorship, supervision and inspection and } \\
\text { insufficient regulatory mechanisms to enforce building codes, } \\
\text { construction guidelines and quality management procedures } \\
\text { during implementation. }\end{array}$ & 8 \\
\hline & $\begin{array}{l}\text { Use of inadequately skilled manpower, poor quality materials and } \\
\text { technology for construction. }\end{array}$ & 6 \\
\hline & $\begin{array}{l}\text { Inadequate pre-qualification of participating organisations, corruption } \\
\text { and lack of competency on the part of implementing organisations. }\end{array}$ & 4 \\
\hline & $\begin{array}{l}\text { Inadequate worker skills assessment, lack of beneficiary participation } \\
\text { and workforce motivation. }\end{array}$ & 4 \\
\hline & $\begin{array}{l}\text { Use of spontaneous imported labour due to pressure for quick rebuild } \\
\text { and short-term targets. }\end{array}$ & 2 \\
\hline \multirow{3}{*}{$\begin{array}{l}\text { Monitoring } \\
\text { and control }\end{array}$} & $\begin{array}{l}\text { Inadequate local institutional capacity to facilitate the monitoring } \\
\text { function for a wide geographical coverage and inadequate beneficiary } \\
\text { participation in the monitoring process. }\end{array}$ & 5 \\
\hline & $\begin{array}{l}\text { Inadequate implementation plans resulting from lack of capacity and } \\
\text { pressure for quick rebuild, inadequate or insufficient experts or } \\
\text { technical personnel for project monitoring, evaluation and control and } \\
\text { inconsistent standards (design and specification) associated with delays } \\
\text { in project monitoring and evaluation. }\end{array}$ & 3 \\
\hline & $\begin{array}{l}\text { Political influence and lack of autonomy of supervisory/monitoring } \\
\text { parties, corruption on the part of stakeholders involved and ineffective } \\
\text { communication between donors, implementing agency, home owners } \\
\text { and monitoring parties leading to poor housing products and affecting } \\
\text { their acceptability. }\end{array}$ & 2 \\
\hline
\end{tabular}

\section{Integrated Measures for Managing Issues in Post-Disaster Housing Reconstruction}

From the analysis of literature and survey data, we identified measures, some context specific, some generally applicable, that could be deployed in managing the issues affecting PHR programmes. These measures have been integrated and organised into categories and with respect to time so that they can be presented in a practically usable format, i.e., the framework for managing PHR shown in Figure 3. At the highest level, the measures have been categorised into phases of the project management life cycle as:

- Preparedness measures

- Initiation measures

- Assessment and planning measures

- Implementation, monitoring and evaluation measures.

In addition to these, there are also categories of measures which apply across more than one of the (preparedness, initiation, assessment and planning, implementation, monitoring and evaluation) stages. We have termed these: 
- Cross-cutting measures.

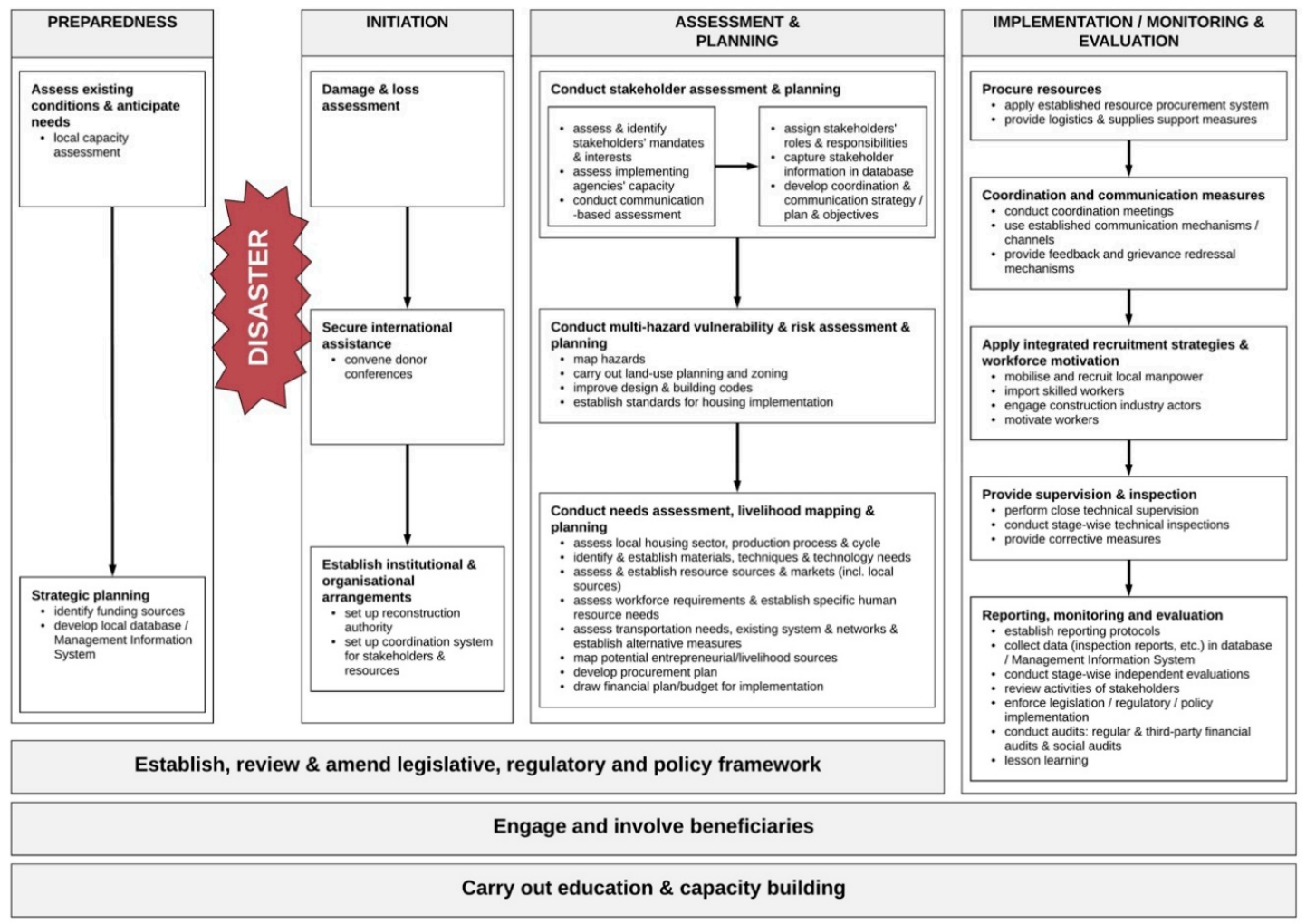

Figure 3. Framework for the management of post-disaster housing reconstruction.

\subsection{Preparedness Measures}

According to expert interviewee I\#16: "there is no particular solution [to lack and/or inadequacy of (human) resources] rather than to be prepared". To minimise the risks and impacts of disasters, vulnerable communities firstly need to be prepared. Preparedness for PHR involves anticipating local capacity needs and planning and prepositioning resources prior to a disaster in order to facilitate effective reconstruction following disasters.

Table 3 shows the preparedness measures identified from the analysis, and these have been organised into two categories.

Table 3. Preparedness measures for PHR.

Assessing Existing Conditions and Anticipating Needs

- Assessment and establishment of skills and expert requirement, materials and financial resource needs and suppliers by designated agencies of government

Strategic planning

- Local capacity building — development of local skill and expertise through education and training

- Establishment/development of local resource database by designated agencies and local councils

- Identification and establishment of alternative funding sources by the national government

\subsection{Cross-Cutting Measures}

Three groups of cross-cutting measures were identified:

- $\quad$ Legislative, regulatory and policy framework

- Engagement and involvement of beneficiaries

- Education and capacity building. 
Since all three of these groups apply to the preparedness stage as well as other, later stages, they are discussed before proceeding with the discussion of the initiation measures for PHR.

\subsubsection{Legislative, Regulatory and Policy Framework}

The need for legislation and regulation $[53,66]$ and policy provision and review by the government were identified as important to provide direction for stakeholders, enable effective management of PHR programmes towards disaster risk reduction, and to facilitate socio-economic recovery of communities. The legislative, regulatory and policy measures identified from the data analysis appear in Table 4.

While some countries may have existing legislation, regulation and policies in place, the need for their review and amendment, as well as the enactment of new legislation and regulation and formulation of new policies, is clear in the preparedness, initiation and assessment and planning stages of PHR. The provision of appropriate legislation, regulation and policies is required to facilitate the effective management of PHR processes and enables PHR programme implementation.

Table 4. Cross-cutting measures for PHR.

\begin{tabular}{l}
\hline Establish, Review and Amend Legislative, Regulatory and Policy Framework \\
\hline - $\quad$ Legislative provision for the establishment of special reconstruction authority \\
- $\quad$ Provision of financial regulations and accounting and reporting policy \\
- $\quad$ Regulations and policy provision to allow external intervention (some) and beneficiary participation \\
- $\quad$ Provision and/or review of legislation governing local resource exploitation \\
- $\quad$ Legislation and policies to enable enforcement/adherence to building codes and land-use regulations \\
- $\quad$ Regulation and policy provision or review to ensure provision and use of health and safety facilities \\
- $\quad$ Regide legislation and policies to mandate local manpower engagement \\
- $\quad$ Pegislation and policy provision to control local resource markets including labour wage escalation \\
\hline Engagement and involvement of beneficiaries \\
\hline (measures appear under their respective stages in Tables 5-7) \\
\hline Education and capacity building \\
\hline
\end{tabular}

- $\quad$ Engage external agencies and experts to provide education and capacity building for strategic management personnel to enable the development of driving policies and to facilitate effective decision-making

- Provide training and capacity building programmes for management personnel to enable effective management of the PHR process

- Education and sensitisation of stakeholders on reconstruction policy direction, legislation, rules, coordination guidelines and need to ensure adherence to building codes and other established standards including other local regulations and cultural practices

- Educate beneficiary communities about risks and the requirement for their involvement and the integration of risk reduction measures during PHR process

- Provision of nationally accredited skill acquisition centres across geographical boundaries to decentralise training and skill development while national level certification is provided for acquired competencies

- Mobilisation, integration and deployment of government administrative structures, INGOs and partner agencies and social institutions for local capacity building

- Provision of education and training for mobilised local manpower to create local capacity to facilitate the construction of safe and resilient housing, provide new economic and livelihood options and for the long-term sustainability of the housing programme

\subsubsection{Engagement and Involvement of Beneficiaries}

While the data analysis identified specific beneficiary engagement measures by the management and/or implementing agencies in the assessment and planning and the implementation, monitoring and evaluation stages, the engagement and involvement of beneficiaries (both as individuals and communities) is clearly essential to all stages of PHR. 
The need for beneficiary (community) engagement by implementing agencies in assessment and planning processes, for instance, was highlighted by I\#8 and I\#17: "local knowledge is very key" to providing information about "construction techniques and technologies, supply chain and resource markets, knowledge of the communities' terrain and environmental conditions, provision of information about alternative transportation system and networks." In terms of monitoring largescale PHR programmes, I\#11 noted that the: "beneficiary (community) is biggest monitoring tool". However, this also has been shown to have limitations-according to I\#8: "their engagement for monitoring PHR may be limited to observation-making and critique of appearance, shabby workmanship and quality of a building and views-sharing on expectations". This calls for sensitization and awareness workshops to enable beneficiaries to identify good construction practice and to effectively monitor the reconstruction process, and it emphasises the link between beneficiary participation and education and capacity building.

Specific beneficiary engagement measures that were identified from the data analysis appear in Tables 5-7 under their respective stages; these have not been separately drawn out and therefore do not appear in Table 4.

\subsubsection{Education and Capacity Building}

Education and capacity building are required to provide requisite local competencies and capacities, risk reduction and resilience development knowledge to strengthen local institutions, aid the development of effective reconstruction policies and decision-making, enhance effective management of the PHR process. and to offer possibilities for turning acquired skills into long-term livelihood opportunities. This includes:

- Training provided to local artisans, new workers and beneficiaries and existing local manpower (with technical guidelines provided as a manual), for construction skills acquisition and upskilling in order to expand skills supplies for PHR.

- Education about legislative and regulatory provisions and/or changes.

- Education of imported manpower on local culture and practices to enable familiarization and adaptation to the local reconstruction environment, etc.

Table 3 shows the example measures identified from the data analysis. Expert interviewee I\#16 noted, however, that local capacity building and training programmes for PHR are long-lead activities: "training new entrant workers does not resolve an ongoing human resource shortage but facilitates long-term project sustainability and recovery".

The long-lead, cross-cutting nature of education and capacity building is reflected in Figure 3. In the preparedness stage, communities are sensitised and educated on their vulnerability and the need to reduce disaster risks, develop knowledge and build capacity. Local capacity is developed for response, to minimise disaster impact, enable quick reconstruction start-up and facilitate the management of PHR programmes. For effective initiation of PHR, education and capacity building are required for strategic and programme-level management personnel to improve disaster risk and reconstruction knowledge to facilitate legislative, regulatory policy provision/review, to strengthen local institutions, enhance stakeholders and resource coordination, and to enable effective management of PHR. In assessment and planning, technical personnel/experts require training on the criteria and methodology for effective assessments and planning. In implementation, the focus is on training, upskilling and on-the-job mentorship for local artisans and supervisory, inspection and monitoring personnel, to enable safe and resilient housing production. In Gujarat, India, for example, training was provided for local masons and, in other cases, beneficiaries during reconstruction to improve the artisans' technical know-how and skills' supply. However, technical guidelines were not developed or provided. See also [67]. 


\subsection{Initiation}

Organisation and mobilisation for a specific PHR programme takes place immediately after a disaster occurs. We have termed this first post-disaster stage for PHR the initiation stage, which includes the following categories of management measures:

- Damage and loss assessment

- Secure international assistance

- Establish institutional and organisational arrangements.

These are introduced and discussed below, and the measures identified from the data under each category appear in Table 5.

Table 5. Initiation measures for PHR.

\section{Damage and Loss Assessment}

- Engage experts to conduct assessment of event impact and identification and classify damaged and/or destroyed houses and resource needs

- $\quad$ Engage beneficiary communities in damage and loss and needs assessment

- Forecast resource requirements for reconstruction to full recovery

\section{Secure International Assistance}

- Calls for international assistance (convene donor conference) to mobilize funds for reconstruction

Establish Institutional and Organisational Arrangements

- Set up reconstruction authority

- Set up coordination system for stakeholders and resources-to coordinate efforts with UN coordination agency and to include donor fund coordination mechanism (multi-donor trust fund or donor basket)

- $\quad$ Multi-level arrangements (as follows):

National Level

Central reconstruction authority

Separate agency/unit to manage stakeholder communication

Financial management unit with experts to provide financial management capacity

Procurement unit to manage logistics and supplies

State/Municipal Level

Multi-tiered institutional/organisational structure at regional/state/district levels to facilitate coordination and monitoring of the programme

\begin{tabular}{l}
\hline Local Level \\
\hline Engage local councils for stakeholder coordination \\
Create development authorities or committees at municipal or local and community levels \\
\hline Project Level \\
\hline Independent supervisory (project management) units at project and/or community levels \\
Engage experts/trained and certified personnel/inspectors for regular inspection and monitoring \\
\hline Beneficiary Community Level \\
\hline Create resident monitoring teams and monitoring committees at local community level \\
Local level (beneficiary) coordination and communication, monitoring and evaluation of the process using local \\
structures such as community leaders, local community organisation or social groups, established local action \\
committee \\
Activate community level efforts through the engagement of community representatives and/or beneficiaries for \\
progress monitoring and supervision \\
\hline External Agencies \\
\hline Collaboration with UN agency to facilitate coordination of other external agencies and for local institutions' \\
capacity building \\
Commission international consultant to monitor reconstruction finance \\
\hline
\end{tabular}




\subsubsection{Damage and Loss Assessment}

To identify disaster impacts, and as a preliminary measure for establishing resource requirements for PHR, our analysis highlighted the need for damage and loss assessment by experts, relevant stakeholders and representatives of the affected community. This enables the identification, classification, quantification and evaluation of the degree of damage and loss to housing, and the forecasting of costs and resource needs for reconstruction. Damage and loss assessment may be conducted using satellite imagery and GIS to map disaster impacts on housing, identify housing needs and to provide data on the number and types of houses affected and their damage severity levels, while household surveys are conducted to capture housing reconstruction and beneficiary needs (I\#5 and I\#15; [68]). In the words of I\#3, "we used GIS mapping to know the number of houses destroyed, how many houses are partly destroyed, how many houses are visibly destroyed. These were the three categories of houses affected".

\subsubsection{Secure International Assistance}

The effective implementation of PHR programmes requires significant resources which vulnerable communities, especially in developing countries, typically lack. To mobilize resources for reconstruction following large-scale disasters, assistance is usually sought by the government from the international donor community through an international donor conference for reconstruction that is typically called at the insistence of the government of the affected country, with preliminary estimates and government's policy direction for PHR informed by the results of the damage and loss assessment exercise referred to above.

\subsubsection{Establish Institutional and Organisational Arrangements}

Our analysis highlighted the need for institutional and organisational arrangements since, as noted by I\#5: "in a lot of developing countries, one of the problems is that, quite often, the local capacity to enforce and monitor is inadequate even in good times. So, in a context like this (post-disaster) where local institutions may have been distorted or destroyed" they may have "lost the capacity to operate". This may be achieved either through establishing new or strengthening existing institutions at the national level to provide "the reconstruction policy, the methodology or approaches and technical guidelines" for PHR (I\#4). An effective institutional and organisational structure also requires decentralisation at regional or state/municipal levels, and the engagement of local councils and local level structures (beneficiaries' communities), so a multi-tiered governance structure is recommended that includes units created or designated to manage aspects such as financial management, logistics and supplies, stakeholder communication, etc. It also involves the engagement of local authorities and beneficiaries (community) to coordinate resources and stakeholders at local levels and to enable the buy-in and participation of beneficiaries while external agencies are engaged for local capacity building. Table 5 expands upon the multi-level institutional structures identified in our analysis:

Central reconstruction authority-The need to strengthen an existing reconstruction authority or establish a new one was identified. A reconstruction authority with a multi-level institutional structure is required to facilitate effective planning of PHR programmes, to coordinate and respond to stakeholders' needs, ensure effective resource utilisation, and to oversee the management and implementation of the PHR programme. The "central reconstruction agency ... brings all parties concerned together at the beginning of the programme and makes clear to every party, their roles and responsibilities" (I\#16).

Coordination system for stakeholders and resources-For effective management of PHR programmes, a coordination system should be established to harmonize the activities of the central reconstruction authority, and local level authorities, UN coordination agency, donor-funds coordination mechanism (e.g., multi-donor trust fund or donor basket), etc. 
UN coordination agency - A UN agency may be designated to coordinate the UN's PHR and community recovery efforts in close consultation with the government (through the reconstruction authority). "In the case of the 50,000 houses built in Sri Lanka, the UN-Habitat coordinated their own programme and other agencies" (I\#4). For the reconstruction programme in Aceh, the United Nation's Office of the Recovery Coordinator (UNORC) was established to coordinate the United Nations agencies' effort and the INGOs involved in reconstruction in consultation with government [69]. When a designated UN agency coordinates the UN's and other reconstruction agencies' PHR efforts, it also facilitates local institutional capacity strengthening for community recovery and long-term project sustainability, while also serving as a channel into the UN system to facilitate UN support for the reconstruction programme.

Multi-donor trust fund or donor basket-Adequate institutional capacity to manage and provide accountability for donor funds is required. According to I\#5, "Some donor agencies were not confident especially with the capacity of the management agencies to disburse funds. There are lots of issues around corruption and how the funds are being spent. So, there would have to be more effort in place to provide and build capacity to enable the disbursement and spending of the funds in an effective manner". In contexts where inadequate financial management capacity and fiduciary risks exist, it is recommended that a multi-donor trust fund (MDTF) is established to pool donor pledges, coordinate reconstruction funds and instill donor confidence in order to facilitate the release of donor pledges. In the reconstruction of Aceh and Nias, for instance, a MDTF was established to pool donor funds to finance and support the government reconstruction efforts. See [70,71]. Where adequate institutional capacity, an effective budgetary system and adequate fiduciary risk measures exist, however, a donor basket may be established to pool donor pledges.

\subsection{Assessment and Planning Measures}

Following initiation of a PHR programme, several assessment and planning functions were identified as necessary for enabling effective implementation. Firstly, considering the multitude of stakeholders available for large-scale PHR, it is required that stakeholders are adequately coordinated. Then, to minimize the exposure of buildings and communities to hazards and to enable the development of resilient structures, a multi-hazard vulnerability assessment of the reconstruction sites is called for. In addition, the affected communities' local housing sector and building production processes should be assessed by experts with the involvement of local community members to facilitate effective production of resilient housing, identify livelihood source areas that beneficiaries can engage in, potential constraints that may affect these, and measures to overcome the identified challenges. See also [72]. These measures are described in more detail below and summarised in Table 6.

\subsubsection{Stakeholder Assessment and Planning}

Stakeholder assessment and planning is required to "provide the coordinating agency an understanding of the different stakeholders, their functions and how to effectively engage them" (I\#6) and to ensure implementing agencies possess the requisite competencies and capacity (I\#6) [73,74]. Stakeholder assessment involves the accreditation and categorisation of stakeholders into groups based on their interests, mandates, function, interconnections, challenges, expectations and contributions. Our analysis highlighted the need for communication-based assessment to "identify their communication needs and challenges" (I\#8), communication channels and first respondents, and to ascertain stakeholders' perceptions and expectations.

To ensure effective stakeholder coordination, roles and responsibilities should be fairly shared and enunciated to avoid gaps and overlaps, minimise redundancy, and to "impede resentment among implementing parties" (I\#12).

A stakeholders' database or management information system where stakeholders' information, assigned roles and responsibilities are collected should be established to enable the effective coordination of participating parties. "We built a 'who-does-what-when' matrix database, where each 
agency's information, assigned roles and responsibilities were collected. Application of the matrix provides information about the agency and the activities the agency is working on, geographical location and the duration of work" (I\#12).

Table 6. Assessment and planning measures for PHR.

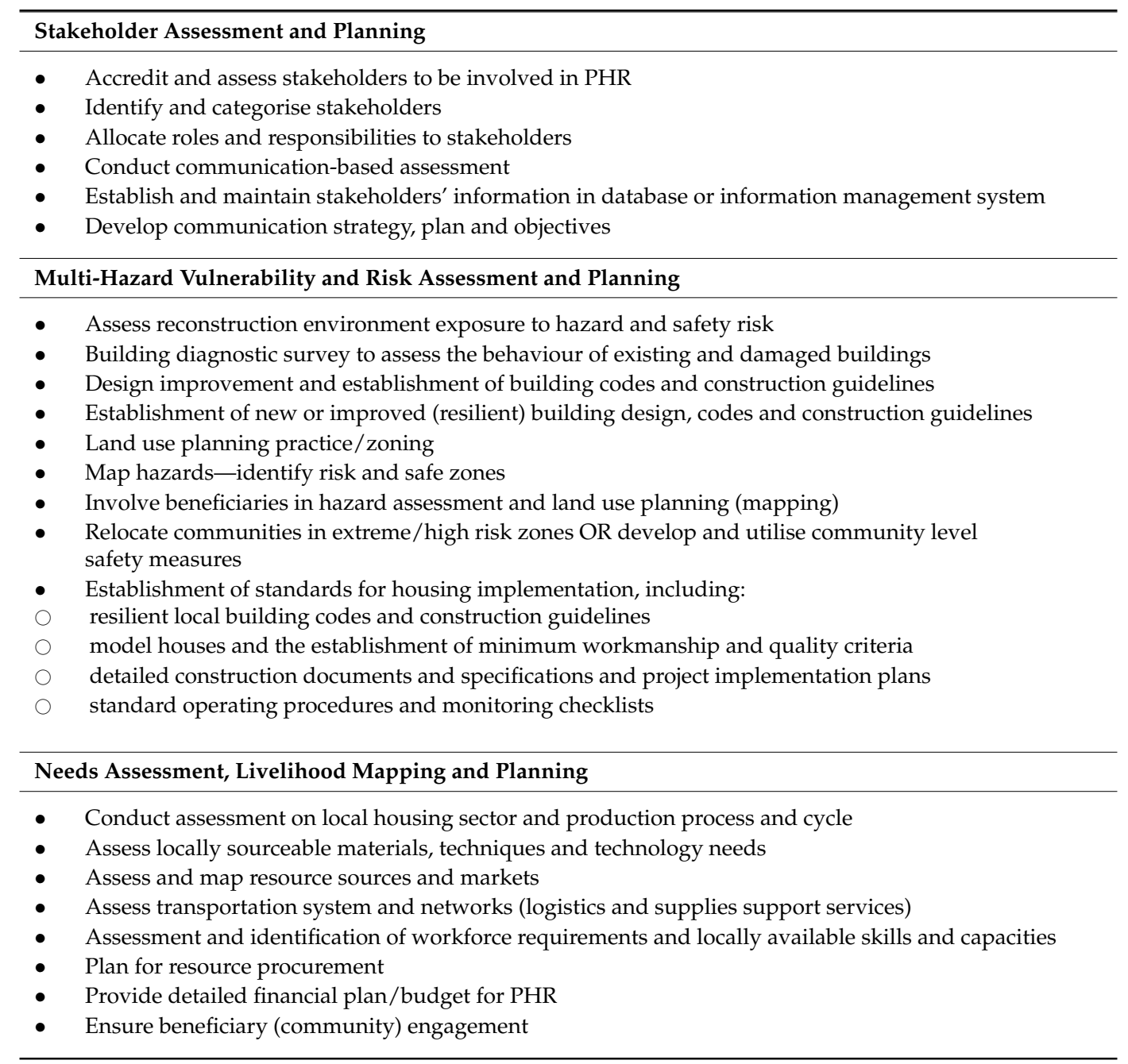

\subsubsection{Multi-Hazard Vulnerability and Risk Assessment and Planning}

Multi-hazard vulnerability and risk assessment enables the review of land-use planning regulation and practice and the development of adequate building (design) codes for the improvement of construction standards and to facilitate resilient reconstruction. According to I\#15, "land use planning should be done to ensure housing are built in safe location". Effective land use planning mitigates communities' exposure to hazard, reduces disaster risk and enables effective development.

Where communities are extremely exposed to disaster risk, the relocation option should be explored. Local councils and affected communities must be involved in multi-hazard vulnerability and risk assessment and decision-making so that they fully buy into relocation, while access to livelihood sources, provision of social infrastructure and the safety of new settlement are all essential for acceptability. Where safe settlement proves difficult, community level safety measures may, however, be applied.

Following the identification and mapping of safe and risk zones, a building diagnostics survey, along with assessment of community disaster risk profile and historical events, is required to inform materials selection, the development of resilient designs, building codes and construction guidelines. Salvaged materials are often used in PHR (I\#1 and I\#7) [61,62], however, "some of the materials are 
unsafe" (I\#7), considering their exposure to hazard, lost strength and the potential health and safety risks. According to I\#5, "the utilisation of salvaged materials must be under risk assessment basis" hence the need for assessment and approval before utilisation. For example, "in Sri Lanka, construction materials to be used in reconstruction were assessed by the National Building Research organisation to ensure they are up to approved standard" (I\#15).

"The biggest measure to ensure the safety of buildings and communities from inherent hazards and health risk ... is the establishment of resilient building codes ... that is based on risk equation" and "... tailored to a local context" (I\#5). I\#9 identified the need for the provision and "strict adherence to construction guidelines to ensure the construction of resilient and safe housing". To enable adherence to building codes and to ensure safe construction practice in reconstruction, "the guideline for rebuild should provide the community the freedom for design and material selection within the financial framework provided" or within the communities' financial capacity (I\#4).

Our analysis identified the need for the establishment of standards such as:

Building codes and construction guidelines-Risk-based, local building codes with guidelines providing detailed building production procedures. For enforcement and adherence, building codes should be enacted into law with techno-social guidance provided for beneficiaries and low-skilled workers to explain the building production process.

Provision of model houses, establishment of minimum workmanship and quality criteria and quality management plan-To enable good workmanship and quality, model houses that are critically reviewed should be provided. See also [67]. The establishment of minimum workmanship and quality standards for building typologies "requires an agreement on the quality standards of housing ... among the donor agencies" (I\#10) and in other cases, "having a proper building contract" to enable conformance and enforcement (I\#9 and I\#13). However, I\#3, I\#15 and I\#17 highlighted the need for an enforceable quality management plan and control procedures.

Detailed construction documents and implementation plan-To enable good workmanship and quality construction standards, detailed construction drawings and approved specifications must be provided. The need to develop and monitor the project implementation plan in collaboration with beneficiaries/homeowners was identified as necessary for defining expectations, to provide a basis for assessing a programme's efficiency, and to help facilitate the maintenance of the housing quality level and activities schedules throughout the production process, thus enabling speed.

Provision of standard operating procedures and monitoring checklist-To ensure effective coordination and management of PHR projects, standardized operating procedures for supervision and inspection, approvals, and monitoring and evaluation are called for. These may be provided at national or state levels, and adapted at other project governance levels. Monitoring checklists should also be provided for each of the building typologies to serve as a basis for inspection and monitoring and ensure compliance with the established standards.

\subsubsection{Needs Assessment, Livelihood Mapping and Planning}

A thorough assessment of the local housing sector and production process/cycle is required to identify resilient housing reconstruction needs and map existing and potential entrepreneurial or livelihood source areas. "As part of assessment, livelihood mapping should be to understand what the community are engaged in ... to inform your planning" (I\#5). The identified measures within needs assessment, livelihood mapping and planning are discussed and summarised in Table 6.

The local housing sector assessment enables the identification of construction materials, techniques and technology options, their disaster resilience characteristics, sufficiency and cultural acceptability, with consideration for health, safety and suitability for the environment. Identified areas of livelihood sources should be mapped while potential constraints are identified to inform planning. "In Pakistan, some of the houses destroyed were big traditional houses that use traditional technology like the stone in mud with planks of wood. We improved the technology for reconstruction ... and we retrained the local people on the knowledge required for rebuilding the houses to be earthquake resistant. We relied 
mostly on local workers and a few international experts .... In fact, we rebuilt over 150,000 houses with this technology called Dhajji construction" (I\#4). The use of local materials, techniques and technology enables quick reconstruction, provides livelihood source options for local communities, reduces logistics costs and enhances acceptability and long-term project sustainability.

To enable effective logistics and supplies for the implementation of PHR, early assessment is required to identify locally available materials, their supply sources or markets and capacity. These should be mapped against the distance to points of use to determine the logistics and supplies requirements and costs. Alternative material sources should be arranged in the case of supply shortages and price variations due to market or seasonal changes. "We identified areas with lots of thickly populated pine trees and lots of stones for Dhajji construction. Where there were no stones and wood, we introduced hollow masonry blocks for reconstruction" (I\#3).

To manage inadequacies or lack of human resources for PHR requires an early assessment to identify specific skills needs, available local competencies and capacities and the constraints that affect skills provision and the implementation of the programme. "You need to have the right kind of combination of local expertise and ... technical knowledge for reconstruction. So, at a certain situation you need to assess the kind of combination that you require, the technical knowledge and the engineering skills and social skills required" (I\#4). Workforce assessment enables effective construction team and budget development and identification of the resources required for workforce capacity building. "In Pakistan where we built over 150,000 houses using Dhajji dewari construction ... the skills required were not complicated, we identified we needed carpenters and Pakistan has a lot of people with construction skills. What we needed was to upskill the artisans, so we had to train a lot of carpenters and masons to give them the knowledge required for building earthquake resistant houses" (I\#4).

An assessment of transportation needs and the condition of the transportation system and networks is required to identify transportation challenges, constraints and their impacts on resource logistics and supplies, and to identify alternatives and areas requiring strategic interventions. I\#13 opined that the resulting issues from the transportation needs assessment "should be resolved before determining the types of materials, number of workers required and overall development cost for reconstruction". To ensure scheduled and cost-effective resource and project delivery, there is a need to identify, plan and mobilise for activities and resources requiring long-lead times.

On the basis of the assessment and identification of resource needs for PHR, detailed financial management and action plans with timescales for which funds are required can be developed. The detailed financial plans enable donors and implementing agencies to identify a project's funding requirements for a given period, mitigate delays in financial disbursement, as well as enable effective monitoring and assessment of PHR performance.

As noted in Section 5.2.2 above, the need for beneficiary (community) engagement in assessment and planning processes for PHR was identified.

\subsection{Implementation, Monitoring and Evaluation Measures}

Following assessment and planning, PHR programmes reach the implementation stage with concurrent monitoring and evaluation, as well as reporting requirements. Analysis of our data highlighted the role of resource procurement, logistics and supplies, stakeholder communication and coordination, workforce recruitment and motivation, supervision and inspection and reporting, particularly auditing, in achieving effective PHR outcomes for community recovery. These measures are described in more detail below and summarised in Table 7. 
Table 7. Implementation, monitoring and evaluation measures for PHR.

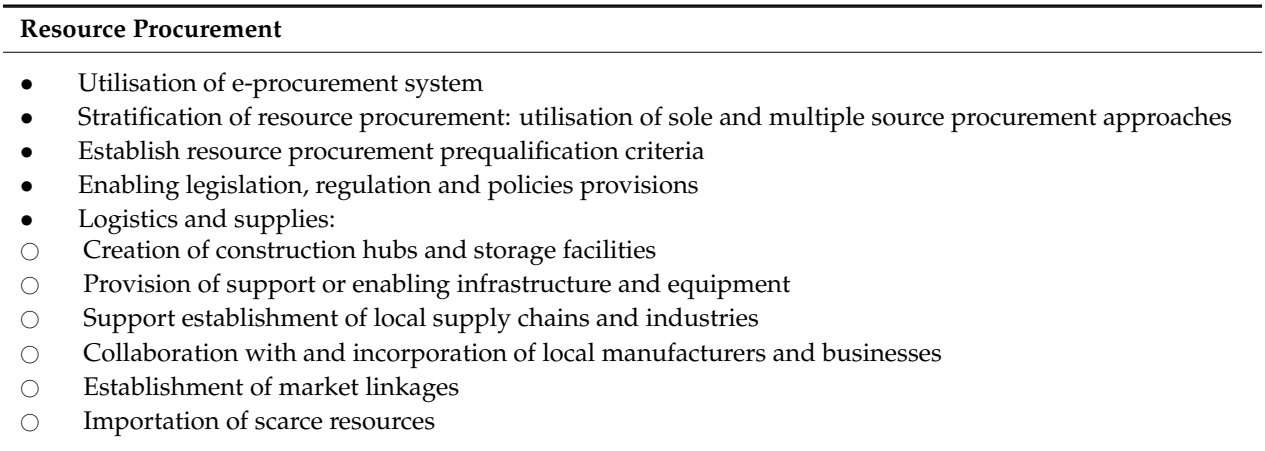

Stakeholder Coordination and Communication

- Establish stakeholder coordination mechanisms, such as setting up a multi-stakeholder platform

- Conducting regular stakeholders' coordination meetings at municipal and local levels

- Establishment of stakeholders' communication mechanisms and channels, such as utilisation of online portals/information management system, community/social forums, social media and mobile communication systems, face-to-face meetings and print media.

- Establishment of communication and reporting protocols

- Establish grievance redressal mechanisms

Recruitment Strategies

- Mobilisation and recruitment of local manpower:

- Engagement of local construction actors with local, regional and international networks to draw skilled workers.

Engagement of social mobilisers, local experts, builders, skilled artisans, volunteers

Active engagement of beneficiaries for housing reconstruction

- Engagement of new graduates and interns of construction disciplines from local academic/training institutions and agencies' staff

- Invitation, recruitment and importation of experts, experienced builders and skilled artisans

- Engagement of construction industry actors

Workforce Motivation

- Provision of market wages, incentives, rewards and livelihood support

- Provision of regular training and capacity building programmes and value for new knowledge acquisition for long-term career growth

- Possibilities of long-term engagement and carrier progression

- Raise social perception of workers' role in the community (humanitarian service)

- Provision of safe and secure work environment including adequate accommodation and transportation

- Use of local construction materials and techniques and participation in reconstruction of own house

- Recognition of workers for good workmanship and engagement in decision-making

Supervision and Inspection

- Provide close technical supervision during housing production

- Engage beneficiaries (community), especially women, in supervision during housing production

- Stratify inspection, certification and payment processes into pre-established construction stages

- Provide independent technical inspection to ensure compliance and enforcement of standards

- Deploy experts and certified technical personnel for stage-wise technical inspection and certification

Reporting, Monitoring and Evaluation Function

- Use management information system or database for reporting and monitoring programme's progress

- Engagement of local councils in PHR project monitoring

- Beneficiary and community engagement in regular monitoring during the implementation

- Stage-wise transfer of cash to beneficiaries

- Auditing:

- Conduct regular and independent financial auditing on reconstruction finances

Conduct technical auditing on new buildings

Conduct social audit

- Engage independent consultant to monitor and evaluate participating organisations' activities

- Lesson learning: conduct regular review and document organizations' performance and lessons learnt 


\subsubsection{Resource Procurement Measures}

The application of an e-procurement system for resource procurement was utilised in Indonesia because it "minimises bureaucracy, procurement periods ... ensures transparency of the procurement process" (I\#10) and enables effective resource supplies for quick delivery of PHR programmes. Resource procurement should be stratified into different categories to enable effective resource delivery and performance based on suppliers' capacity, while both single sourcing and multiple source procurement approaches are utilised accordingly. Whereas single sourcing reduces unnecessary logistics and bureaucracy, procurement periods and transaction costs, and enables simplified and efficient resource supplies [75,76], multiple sourcing enables "competitiveness for the best value", "contributes to local economy" and provides "multiplier effect for the development of local supply chain" (I\#1). Multiple sourcing also mitigates the risk of supplier failure, facilitates the availability of suppliers and material supplies and encourages community participation and emergence of local entrepreneurs, all of which assist in the revival of the local economy. Considering the merits of both single and multiple sourcing, "economic and financial analysis" (I\#1) may be conducted to ascertain the most suitable procurement approach. "The ideal approach would consider diversifying (resource procurement) to the extent possible to target the potential for local production, ... prioritise national resources ... boost the potential for local entrepreneurs to emerge", while giving consideration for "the tendencies of getting economies of scale" (I\#1).

In engaging logistics and supplies organisations for PHR, supplier prequalification criteria, including organisational capacity, financial strength, capabilities for effective resource delivery and procurement experience in the post-disaster context should be assessed. Further prequalification criteria may include knowledge of local resource sources/markets that would favour local industries and businesses and facilitate local community recovery.

To facilitate logistics and supplies, essential support services and/or measures are required from the government (reconstruction authority), for instance, a temporary road network is required to facilitate resource delivery and market linkages, minimise resourcing challenges, reduce time and cost, and ensure good quality materials supplies and protection following delivery.

\subsubsection{Stakeholder Coordination/Communication Mechanism/System}

For effective stakeholder coordination, the reconstruction management agency should, at the inception of the programme, create a multi-stakeholder platform that regularly brings all participating stakeholders together for periodic meetings (I\#7, I\#8, I\#9, I\#10, I\#11, I\#13 and I\#16). "In Nepal, Housing Recovery and Reconstruction Platform (HRRP) has been created where we have periodic meetings" (I\#11). Conducting regular coordination meetings in a generally understandable language (I\#9), enables periodic project review, helps with knowledge and experience sharing and ensures stakeholder collaborations and inclusiveness. "In West Sumatra, we talked about issues and shared problems, visited each other's projects to learn from each other and then we involved in training the facilitators for the community-based housing" (I\#10). The multi-stakeholder platform aids stakeholder coordination and collaboration and improves PHR effectiveness "because of the knowledge and information shared and built trust among stakeholders" (I\#10). Project reviews, experiences shared, lessons learnt from previous and ongoing projects, and minutes of coordination meetings should all be coordinated, documented and utilised for future projects and should be communicated to participating parties after the coordination meetings, with participating parties also giving their feedback on the meetings (I\#8, I\#12 and I\#15).

\subsubsection{Workforce Recruitment and Alternative Strategies}

To manage the human resource shortages in large-scale PHR, various alternative recruitment measures were identified: 
Mobilisation and recruitment of local manpower-Local recruitment is crucial. While a lack of workers at strategic and project management levels can be managed by drawing staff between agencies, local builders, skilled artisans and beneficiaries can be engaged to create the workforce required for the management and implementation of housing production while new graduates and interns of construction disciplines can be engaged to support operational management needs. The need for social mobilisers for local manpower organisation was also identified.

Advantages of local manpower recruitment include that it enables the utilisation of local resources, indigenous skills and techniques, and facilitates "development of local capacities for long-term sustainability of the programme" (I\#5); it also creates employment and livelihood source options and enables the alignment of beneficiary needs. Beneficiary engagement in supervision, especially by women, reduces unethical construction practices and "helps to ensure their houses are adequately built to ensure quality" (I\#3), as well as providing beneficiaries with a sense of ownership and reducing problems with satisfaction and acceptability. I\#5 and I\#16 and [11] observe that local manpower engagement is more effective for simple buildings constructed under minimal pressure; analysis shows that inconsistent workmanship and quality issues arise with local manpower recruitment so that there is a corresponding need for education, training and capacity building.

Skilled workers importation-Although the importation of workers is often "challenged by visa ... local trade association and licensing issues" (I\#8), I\#11 argued that the importation of skilled workers should be for training and capacity building purposes to develop local competencies. Our analysis and evidence from previous studies, including [23,77-79], suggests that importing workers for PHR denies local livelihood opportunities and encourages capital flight, reduces local knowledge transfer and impacts acceptability, maintainability and beneficiaries' sense of ownership. Thus, it affects the socio-economic recovery of beneficiary communities and long-term sustainability of the programme. I\#16 emphasised that "the effective measure to resolving manpower shortages is to prepare locals before disasters".

Engagement of construction industry actors-The engagement of construction industry actors to apply their management expertise and networks in order to resolve the lack of or inadequate workforce for PHR was also identified. Although engaging construction industry actors provides the competence and capacity required for speed, quality and resilient PHR, their engagement also creates a "tension between the need for short-term delivery and ... long-term sustainability of recovery projects" (I\#5) [79]. To facilitate the achievement of the wider outcome goals of PHR, "a certain degree of contractors should be allowed but forced to help develop local skills and competencies particularly on the utilisation of new materials and technology and for long-term sustainability of the project" (I\#5).

\subsubsection{Workforce Motivation}

Motivation is required to inspire workers' enthusiasm for efficiency, performance and retention, and to enable beneficiary participation in PHR projects. According to I\#5, "unless those people deployed for reconstruction have passion for the work, you cannot achieve effective implementation, so they need to be motivated". Motivational measures necessary to raise workers' enthusiasm and enable their retention and performance in PHR are listed in Table 7. However, motivating workers in PHR, particularly by increasing wages to enable workforce retention, may "end up with wage escalation ... due to demand for skilled workers and that may necessitate the need to control the market or fixing wages to ensure donors and implementing agencies do not end up in competition with one another to have the best staff" (I\#5). Hence the need for donor and implementing agencies to collaborate and agree appropriate wage levels (I\#5 and I\#9).

\subsubsection{Supervision and Inspection}

To ensure effective integration of risk reduction measures and the achievement of workmanship and housing quality standards, our analysis highlighted the need for effective supervision and inspection. Adequate supervision can be achieved through the deployment of technical personnel 
to provide regular and close technical supervision. However, a lack of capacity often results in ineffective supervision, poor workmanship and housing quality in large-scale PHR. According to I\#10, the provision of adequate "supervisory capacity during production requires some flexibility". That can be achieved by "tailoring local needs and capacity into the reconstruction process", through home-owner/beneficiary participation, "due to their availability" and "interest in the success of their own house" (I\#3). Beneficiary engagement (especially of women) in the supervision and the management of the housing production process enables quick delivery of good quality housing that helps to reduce overall housing reconstruction costs and aids alignment of the beneficiary needs during implementation. Education and training are, however, required to develop the skills needed for effective supervision and management of the process. In supervision, mentoring should be provided for new entrants by skilled and experienced technical personnel to develop local capacity for supervision, implementation and long-term sustainability of PHR programmes through maintenance.

The need to stratify inspection, monitoring and payment processes into pre-established construction stages was highlighted. In Pakistan, "we divided the level of construction into four basic levels to enable effective inspection, monitoring and payments" (I\#3). Technical inspection at pre-established project stages by an independent agency or third-party experts ensures the integration of risk reduction measures and that the expected quality standards are achieved before approvals are given and payment certificates are issued. Stage-wise inspection facilitates construction of safe buildings, effective progress monitoring, and helps in tracking financial resource disbursements for transparency and accountability purposes. To ensure adherence to local building regulations and the alignment of reconstruction housing with approved plans, local councils should also be engaged in inspection.

\subsubsection{Reporting, Monitoring and Evaluation}

To effectively monitor, track and report progress, compliance and financial resource use, various measures were identified as required including:

Reporting and utilisation of management information system/database-The need for the development of a management information system/database has already been discussed above and its utilisation to collect and make accessible all reporting was highlighted in our analysis for transparency, accountability and efficiency in monitoring PHR programmes. "In Aceh, to monitor and control reconstruction projects, one of the requirements is the use of RAN (Recovery Aceh-Nias) database. All agencies and experts involved in the reconstruction programme register on the database, update their project information and report on funds committed or allocated, disbursed and progress made" (I\#10). The reporting of project information in the database enables monitoring parties at different levels to track progress, funds utilisation, compliance with standards, etc., and enables the identification of problem areas and corresponding needs for an effective intervention.

Beneficiary and community engagement-The importance of beneficiary and community engagement in monitoring has already been discussed in Section 5.2.2 above. A further measure identified as enabling effective monitoring of PHR projects is through cash-transfers to beneficiaries' accounts: "In Sri Lanka ... payments were made on the basis of work done and ... for construction-related activities ... on a stage-wise basis" (I\#1). Although I\#1 opines that the transfer of reconstruction funds to beneficiaries' accounts is "extremely useful in owner driven" and/or community driven approaches, cash-transfers to beneficiaries' accounts on a stage-wise basis after work progress and quality assessments "gives locals opportunities to participate in the process" (I\#14). They also enable effective project monitoring, minimise the chances for corruption, "establish transparency" (I\#4) and accountability, since "everyone knows how much money is going in and at what stage" (I\#4), and they also lower transaction costs.

Local council involvement-Local councils' involvement "ensures that what is in the approved plan and reconstruction guidelines is what is being built" (I\#15), thus it facilitates adherence to local building regulations. Local councils should be engaged from the outset of PHR projects to 
establish a participatory working mechanism, in the provision of financial accounting and reporting standards and the provision of an independent monitoring mechanism to enable transparency and accountability [80]. Local council involvement in monitoring and evaluation also enables the development of their institutional capacity to facilitate the establishment of local regulations and standards, participatory project monitoring and evaluation, and to ensure transparency, accountability and long-term sustainability of the PHR programme.

Auditing-Auditing provides assurance to stakeholders on construction quality, financial transparency and accountability of the PHR process. Auditing requirements in PHR include regular internal and third-party financial audits, third-party quality audits and social audits. Regular internal and third-party financial audits provide assurance on effective utilisation and management of reconstruction funds. I\#1 noted, however, that: "conducting audits is not just enough but personnel should be warned that auditing will be conducted" with defaulting personnel or agencies sanctioned according to regulations to serve as a deterrent to mitigate further deviant practices. Third-party technical quality audits to certify that reconstructed buildings comply with minimum quality and design standards, local building codes and other conditions should be conducted by expert inspectors and corrective measures taken where problems are discovered. As a measure to evaluate PHR programmes, analysis identified the requirement for social audits. A social audit, which "should be conducted at community and/or project levels" (I\#17) and at the insistence of the beneficiary communities and other key stakeholders, "allows communities to have more say regarding holding ... donors, reconstruction partners and implementing agencies to account" (I\#5). Social audits are required to assess and improve the impact of PHR programmes, and to ensure effective financial resource utilisation through value provision, beneficiaries' satisfaction and the development of resilient communities. Social audits can be conducted through commissioned surveys or community scorecards conducted by third-party consultants or through community-based organisations, with results made available to bring about improvements to existing and future projects.

Lessons learnt-Lessons from the successes and failures of organisations' performances in the PHR programme must be captured. A third-party consultant should be engaged by the reconstruction management authority to review the activities of the reconstruction agencies to draw out and document lessons and enable continuous improvement in the management of current and future PHR programmes.

\section{Framework for the Management of PHR}

Figure 3 represents all the measures described above as an integrated whole, with each key category of management measures arranged with respect to time and precedence, and with some important management measures included for illustration under each category. Space and clarity limitations prevent the full complement of identified measures from being included under each category within this article, but a larger-scale poster could certainly and usefully contain more information while adhering to the same general layout. The authors' intention is to propose an overall, evidence-based framework for PHR management practice which can serve as a guide to practitioners and policy-makers, in particular, but which is also useful for PHR researchers. The framework is focused at a level of detail which applies generally to all PHR situations. In this way, it is not context-specific but can and should be adapted and developed according to any specific geographic/community/post-disaster context. The framework should be considered to be limited to developing countries as the evidence on which it is based is almost entirely from PHR experiences in the developing world.

\section{Conclusions}

Permanent housing reconstruction (PHR) is an essential part of post-disaster reconstruction programmes. If well managed, it minimises communities' vulnerability to disaster risk and facilitates their recovery and resilience. PHR has historically, however, been one of the least 
successful international development and/or humanitarian sectoral interventions due to the ineffective management of the reconstruction process. The study aim was to develop a framework for the effective management of post-disaster housing reconstruction. This was achieved through a qualitative research approach incorporating evidence obtained from academic and grey literature, practitioner databases, a case study to evaluate the outcome expectations of stakeholders, and an experts' opinion survey to draw "good practice" measures. On the basis of the evidence drawn from all these sources, the management issues affecting post-disaster housing reconstruction were identified, the outcome goal expectations for PHR were investigated, and management measures to deal with the issues and meet the outcome expectations were determined. Key among the measures identified include:

- The strategic importance of communities' preparedness. The assessment of existing conditions, vulnerabilities, needs and capacities, and the strategic planning of local capacity building and prepositioning of resources to enable the community to respond appropriately in terms of reconstruction.

- The need for sound initiation of the reconstruction programme based on a thorough damage and loss assessment, and taking into consideration the needs of affected communities towards mitigating potential future hazards. Securing international assistance is crucial to effective initiation of large-scale housing reconstruction programmes and the achievement of reconstruction outcomes since it enables the provision of financial aid and resources to the affected community (including the most vulnerable members). This enhances disaster risk reduction by enabling the reconstruction of safe and resilient housing and helps to resolve underlying social and economic issues. The study identified the need for the establishment of multi-level institutional and organisational arrangements at national and/or state levels to facilitate programme management and the coordination of stakeholders and resources. It is also crucial that local level administrative and organisational structures are strengthened and engaged to enable the buy-in of the beneficiary communities and allow them to take ownership of the programme, which, in turn, facilitates community recovery and long-term sustainability of the programme.

- The establishment of a legislative, regulatory and policy framework that provides direction for stakeholders, enables adherence to established standards and facilitates effective PHR programme management.

- The need for critical assessment of communities' vulnerability and identification of existing and underlying hazards and disaster risks. Assessment of stakeholders and resource needs is required to enable the development of standards and enables disaster risk reduction and effective implementation of the programme.

- The need for beneficiary community engagement in the reconstruction process is essential to give them ownership of the programme, ensure adherence to risk reduction measures, enable the development of local capacities to support social and economic revival of the community and for project sustainability.

- The provision of education and capacity building for stakeholders throughout the PHR management process, which facilitates all aspects of programme implementation and the long-term sustainability of PHR programmes.

In integrating and organising the identified measures with respect to time, the authors propose an overall framework for the management of post-disaster housing reconstruction which is aimed at providing general guidance to practitioners and policy-makers. This practice framework suggests the application of a participatory strategy in the management of large-scale permanent housing reconstruction programmes in order to achieve a programme's intended outcomes. The study focused largely on the reconstruction phase of the disaster management cycle with particular emphasis on permanent housing reconstruction. Given the singularity, complexity and catastrophic nature of post-disaster contexts, this framework for practice will need to be adapted to different, specific post-disaster reconstruction situations. 
The proposed framework is also of potential interest to the PHR research community and future research is recommended to apply, evaluate, validate and refine the framework in practice.

Author Contributions: The following contributions were made by each author: conceptualization, methodology, analysis, writing — original draft preparation, A.A.B.; writing-review and editing, supervision, visualization, E.W.; visualization, supervision, project administration, funding acquisition, I.L.

Funding: This research was supported by the Advancing Skill Creation to ENhance Transformation (ASCENT) project co-funded by the Erasmus+ Programme of the European Commission and by institutional research funding of the Estonian Government's Ministry of Education and Research IUT1-15 “Nearly-Zero energy solutions and their implementation on deep renovation of Buildings". The funding parties' (European Commission and Estonian Government) support for the production of this publication does not constitute an endorsement of the contents which reflect the views only of the authors, and they cannot be held responsible for any use which may be made of the information contained therein.

Conflicts of Interest: The authors declare no conflict of interest.

\section{References}

1. Pérez-Fructuoso, M.J. Economic damages and the impact of natural or anthropic disasters: Main features of an evaluation framework. Risk Manag. 2007, 98, 22-42.

2. Ahmed, I.; Charlesworth, E. Post-disaster housing reconstruction to enable resilient communities. Open House Int. 2014, 39, 4-6.

3. Ingirige, B.; Gayan, W.; Amaratunga, D. Building up resilience of construction sector SMEs and their supply chains to extreme weather events. Int. J. Strateg. Prop. Manag. 2010, 4, 362-375. [CrossRef]

4. Schilderman, T. Adapting traditional shelter for disaster mitigation and reconstruction: Experiences with community-based approaches. Build. Res. Inf. 2004, 32, 414-426. [CrossRef]

5. Ahmed, I. An overview of post-disaster permanent housing reconstruction in developing countries. Int. J. Disaster Resil. Built Environ. 2011, 2, 148-164. [CrossRef]

6. Lindell, M.K. Recovery and reconstruction after disaster. In Encyclopedia of Natural Hazards 2013; Springer: Dordrecht, The Netherlands, 2013; pp. 812-824.

7. Lyons, M. Building Back Better: The Large-Scale Impact of Small-Scale Approaches to Reconstruction. World Dev. 2009, 37, 385-398. [CrossRef]

8. Lang, H. Community housing in post disaster area on Nias islands, Indonesia: Responding to community needs. In Proceedings of the 4th International i-Rec Conference, University of Canterbury, Christchurch, New Zealand, 30 April-2 May 2008.

9. Haigh, R.; Siri, H.; Sakalasuriya, M.; Vickneswaran, G.; Weerasena, N. Post-disaster housing reconstruction in conflict affected Sri Lanka. Disaster Prev. Manag. 2016, 25, 566-580. [CrossRef]

10. Lizarralde, G. Organizational design, performance and evaluation of post-disaster reconstruction projects. In Proceedings of the First International Conference on Post-Disaster Reconstruction: Improving Post-disaster Reconstruction in Developing Countries, Universite de Montreal, Montreal, QC, Canada, 23-25 May 2002.

11. Barakat, S. Housing Reconstruction after Conflict and Disaster; Network Papers; Humanitarian Policy Group: London, UK, 2003; Volume 43, pp. 1-40.

12. Barenstein, J.D. Housing Reconstruction in Post-Earthquake Gujarat: A Comparative Analysis; Humanitarian Practice Network; Overseas Development Institute: London, UK, 2006.

13. Haigh, R.; Amaratunga, D. An integrative review of the built environment discipline's role in the development of society's resilience to disasters. Int. J. Disaster Resil. Built Environ. 2010, 1, 11-24. [CrossRef]

14. Sphere Project. Humanitarian Charter and Minimum Standards in Humanitarian Response; Practical Action Publishing: Rugby, UK, 2011.

15. Quarantelli, E. Sheltering and Housing after Major Community Disasters: Case Studies and General Observations; Ohio State University: Columbus, OH, USA, 1982.

16. Hosseini, S.A.; Pons, O.; Arroyo, C.M.; de la Fuente, A. Identifying Temporary Housing Main Vertexes through Assessing Post-Disaster Recovery Programs. World Academy of Science, Engineering and Technology. Int. J. Civ. Environ. Struct. Constr. Archit. Eng. 2016, 10, 1308-1315.

17. Oliver-Smith, A. Successes and failures in post-disaster resettlement. Disasters 1991, 15, 12-23. [CrossRef] [PubMed] 
18. Hayles, C.S. An examination of decision making in post disaster housing reconstruction. Int. J. Disaster Resil. Built Environ. 2010, 1, 103-122. [CrossRef]

19. Davidson, C.H.; Johnson, C.; Lizarralde, G.; Dikmen, N.; Sliwinski, A. Truths and myths about community participation in post-disaster housing projects. Habitat Int. 2007, 31, 100-115. [CrossRef]

20. Coffey, V.; Trigunarsyah, B. Rebuilding housing after a disaster: Factors for failure. In Proceedings of the 8th Annual International Conference of the International Institute for Infrastructure, Renewal and Reconstruction (IIIRR), Kumamoto University, Kumamoto, Japan, 23 April 2012; pp. 292-300.

21. Ismail, D.; Majid, T.A.; Roosli, R.; Ab Samah, N. Project Management Success for Post-disaster Reconstruction Projects: International NGOs Perspectives. Procedia Econ. Financ. 2014, 18, 120-127. [CrossRef]

22. Alexander, D. Planning for Post-disaster Reconstruction. Presented at the I-Rec 2004 International Conference on Improving Post-Disaster Reconstruction in Developing Countries, Coventry, UK, 22-23 April 2004.

23. Da Silva, J. Lessons from Aceh. Key Considerations in Post-Disaster Reconstruction; Practical Action Publishing: Wawickshire, UK, 2010.

24. Ismail, D.; Roosli, R.; Ab Samah, N. A Review On Post-Disaster Reconstruction Project: Issues and Challenges Faced by International Non-Governmental Organisations (INGOs). In Proceedings of International PostGraduate Seminar (IPGS 2014), "Engineering Challenges Towards Better Life and Humanity"; Universiti Teknologi MARA: Shah Alam, Malaysia, 2014; p. 72.

25. Steinberg, F. Housing reconstruction and rehabilitation in Aceh and Nias, Indonesia-Rebuilding lives. Habitat Int. 2007, 31, 150-166. [CrossRef]

26. Félix, D.; Branco, J.M.; Feio, A. Temporary housing after disasters: A state of the art survey. Habitat Int. 2013, 40, 136-141. [CrossRef]

27. Mannakkara, S.; Wilkinson, S. Re-conceptualising “Building Back Better" to improve post-disaster recovery. Int. J. Manag. Proj. Bus. 2014, 7, 327-341. [CrossRef]

28. Kennedy, J.; Ashmore, J.; Babister, E.; Kelman, I.; Zarins, J. Water and Urban Development Paradigms, Disaster Mitigation Lessons from "Build Back Better" Following the 26 December 2004 Tsunamis; Feyen, J., Shannon, K., Neville, Eds.; Taylor \& Francis Group: London, UK, 2009; pp. 297-302. ISBN 978-0-415-48334-6.

29. Asgary, A.; Badri, A.; Rafieian, M.; Hajinejad, A. Lost and used post-disaster development opportunities in Bam earthquake and the role of stakeholders. In Proceedings of the International Conference and Student Competition on Post-Disaster Reconstruction: Meeting Stakeholder Interests, Florence, Italy, 17-19 May 2006.

30. Bosher, L. Hazards and the Built Environment: Attaining Built-in Resilience; Taylor \& Francis: London, UK; New York, NY, USA, 2008.

31. Akadiri, P.O.; Chinyio, E.A.; Olomolaiye, P.O. Design of a sustainable building: A conceptual framework for implementing sustainability in the building sector. Buildings 2012, 2, 126-152. [CrossRef]

32. Vahanvati, M. A novel framework for owner driven reconstruction projects to enhance disaster resilience in the long term. Disaster Prev. Manag. 2018, 27, 421-446. [CrossRef]

33. International Federation of the Red Cross \& Red Crescent (IFRC). Understanding Community Resilience and Program Factors that Strengthen Them: A Comprehensive Study of Red Cross Red Crescent Societies Tsunami Operation, June 2012, Geneva, Switzerland. Available online: http:/ /www.ifrc.org/PageFiles / 96984/Final_Synthesis_Characteristics_Lessons_Tsunami.pdf (accessed on 25 October 2012).

34. Kapucu, N.; Hawkins, C.V.; Rivera, F.I. Disaster Resiliency: Interdisciplinary Perspectives; Routeledge: New York, NY, USA, 2013.

35. United Nations International Strategy for Disaster Reduction (UNISDR). Sendai Framework for Disaster Risk Reduction 2015-2030; UNISDR: Geneva, Switzerland, 2015.

36. ALNAP. ALNAP Annual Review 2002, Humanitarian Action: Improving Performance through Improved Learning; ODI: London, UK, 2002.

37. ALNAP. Humanitarian Action: Improving Monitoring to Enhance Accountability and Learning. London; ODI: London, UK, 2003.

38. Lloyd-Jones, T. Mind the Gap! Post-Disaster Reconstruction and the Transition from Humanitarian Relief; RICS: London, UK, 2006.

39. Ozden, A.T. Developing a model for community involvement in post-disaster housing programmes. In Proceedings of the 2006 International Conference and Student Competition on Post-Disaster Reconstruction, Florence, Italy, 17-19 May 2006. 
40. Jamshed, A.; Rana, I.A.; Khan, M.A.; Agarwal, N.; Ali, A.; Ostwal, M. Community participation framework for post-disaster resettlement and its practical application in Pakistan. Disaster Prev. Manag. 2018, 27, 604-622. [CrossRef]

41. Bilau, A.A.; Witt, E. An analysis of issues for the management of post-disaster housing reconstruction. Int. J. Strateg. Prop. Manag. 2016, 20, 265-276. [CrossRef]

42. Bilau, A.A.; Witt, E.; Lill, I. A Framework for Managing Post-disaster Housing Reconstruction. Procedia Econ. Financ. 2015, 21, 313-320. [CrossRef]

43. Bilau, A.A.; Witt, E.; Lill, I. Analysis of Measures for Managing Issues in Post-Disaster Housing Reconstruction. Buildings 2017, 7, 29. [CrossRef]

44. Bilau, A.A.; Witt, E.; Lill, I. Housing reconstruction following the 2012 Nigerian floods: Was it built back better? In Proceedings of the CIB World Building Congress 2016, Tampere, Finland, 30 May-3 June 2016; Volume 2.

45. Bilau, A.A.; Witt, E.; Lill, I. Research methodology for the development of a framework for managing post-disaster housing reconstruction. Procedia Eng. 2018, 212, 598-605. [CrossRef]

46. Malalgoda, C.; Amaratunga, D. A disaster resilient built environment in urban cities: The need to empower local governments. Int. J. Disaster Resil. Built Environ. 2015, 6, 102-116. [CrossRef]

47. Mannakkara, S.; Wilkinson, S. Build back better: Lessons from Sri Lanka's recovery from the 2004 Indian Ocean tsunami. Int. J. Architect. Res. 2013, 7, 108-121.

48. Mannakkara, S.; Wilkinson, S. Build. Back Better Applications for Stakeholder Management in Post-Disaster Environments; Earthquake Engineering Research Institute: Oakland, CA, USA, 2013.

49. United Nations Office for Disaster Risk Reduction (UNISDR). Terminology on Disaster Risk Reduction. Geneva: UNISDR. 2017. Available online: https://www.unisdr.org/we/inform/terminology (accessed 16 October 2018).

50. Bosher, L.; Dainty, A.; Carrillo, P.; Glass, J.; Price, A. Integrating disaster risk management into construction: A UK perspective. Build. Res. Inf. 2007, 35, 163-177. [CrossRef]

51. Wamsler, C. Mainstreaming risk reduction in urban planning and housing: A challenge for international aid organisations. Disasters 2006, 30, 151-177. [CrossRef] [PubMed]

52. Clinton, W.J. Lessons Learned from Tsunami Recovery: Key Propositions for Building Back Better; Office of the UN Secretary-General's Special Envoy for Tsunami Recovery: New York, NY, USA, 2006.

53. Mannakkara, S.; Wilkinson, S. Post-disaster legislation for building back better. Constr. Law J. 2013, 29, 495-506.

54. Bosher, L.; Dainty, A. Disaster risk reduction and 'built-in'resilience: Towards overarching principles for construction practice. Disasters 2011, 35, 1-18. [CrossRef] [PubMed]

55. Reifels, L.; Pietrantoni, L.; Prati, G.; Kim, Y.; Kilpatrick, D.; Dyb, G.; Halpern, J.; Olff, M.; Brewin, C.R.; O'Donnell, M. Lessons learned about psychosocial responses to disaster and mass trauma: An international perspective. Eur. J. Psychotraumatol. 2013, 4. [CrossRef] [PubMed]

56. Mooney, M.F.; Paton, D.; de Terte, I.; Johal, S.; Karanci, A.N.; Gardner, D.; Collins, S.; Glavovic, B.; Huggins, T.J.; Johnston, L.; et al. Psychosocial recovery from disasters: A framework informed by evidence. N. Z. J. Psychol. 2011, 40, 26-38.

57. ALNAP. Literature Review for Shelter After Disaster 2011. Available online: http://www.alnap.org/ resource/7725 (accessed on 9 March 2016).

58. International Federation of Red Cross and Red Crescent Societies (IFRC). Owner-Driven Housing Reconstruction Guidelines; New York, NY, USA, 2010; p. 208.

59. Sadiqi, Z.; Trigunarsyah, B.; Coffey, V. A framework for community participation in post-disaster housing reconstruction projects: A case of Afghanistan. Int. J. Proj. Manag. 2017, 35, 900-912. [CrossRef]

60. Lyons, M.; Schilderman, T. Putting People at the Centre of Reconstruction; PCR Position Paper; Practical Action: Rugby, UK, 2010.

61. Ophiyandri, T.; Amaratunga, R.; Pathirage, C. Community based post disaster housing reconstruction: Indonesian perspective. In Proceedings of the CIB 2010, Salford, UK, 10-13 May 2010.

62. Kennedy, J.; Ashmore, J.; Babister, E.; Kelman, I. The meaning of 'build back better': Evidence From post-tsunami Aceh and Sri Lanka. J. Conting. Crisis Manag. 2008. 16, 24-36. [CrossRef] 
63. Niazi, Z.; Anand, C. Post-tsunami reconstruction in South India: Lessons for habitat development, In Participatory Design and Appropriate Technology for Disaster Reconstruction, Proceedings of the 2010 International i-Rec Conference, Ahmedabad, India, 15-20 July 2010; Lizarralde, G., Jigyasu, R., Vasavada, R., Havelka, S., Duyne Barenstein, J., Eds.; Groupe de Recherche IF, GRIF, Université de Montréal: Montreal, QC, Canada, 2010; pp. 110-122.

64. Chang, Y.; Wilkinson, S.; Potangaroa, R.; Seville, E. Resourcing for post-disaster reconstruction: A comparative study of Indonesia and China. Disaster Prev. Manag. 2012, 21, 7-21. [CrossRef]

65. Ophiyandri, T.; Amaratunga, D.; Pathirage, C.; Keraminiyage, K. Critical success factors for community-based post-disaster housing reconstruction projects in the pre-construction stage in Indonesia. Int. J. Disaster Resil. Built Environ. 2013, 4, 236-249. [CrossRef]

66. Rotimi, J.O.; Wilkinson, S.; Zuo, K.; Myburgh, D. Legislation for effective post-disaster reconstruction. Int. J. Strateg. Prop. Manag. 2009, 13, 143-152. [CrossRef]

67. Vahanvati, M.; Mulligan, M. A new model for effective post-disaster housing reconstruction: Lessons from Gujarat and Bihar in India. Int. J. Proj. Manag. 2017, 35, 802-817. [CrossRef]

68. Skat-International Federation of Red Cross and Red Crescent Societies (IFRC). Sustainable Reconstruction in Urban Areas. A Handbook; IFRC: New York, NY, USA, 2012.

69. Office for the UN Recovery Coordinator for Aceh and Nias (UNORC), Indonesia: Office for the UN Recovery Coordinator for Aceh and Nias. Monthly Update-Mar 2007. 31 March 2007. Available online: https: / reliefweb.int/report/indonesia/indonesia-office-un-recovery-coordinator-aceh-and-niasmonthly-update-mar-2007 (accessed 14 July 2016).

70. Fengler, W.; Ihsan, A.; Kaiser, K. Managing Post-Disaster Reconstruction Finance; World Bank Publications: Washington, DC, USA, 2008.

71. McKeon, J.; Masyrafah, H. Post Tsunami Aid Effectiveness in Aceh: Proliferation and Coordination in Reconstruction; Working Paper; Wolfensohn Center for Development: Washington, DC, USA, 2008.

72. Schilderman, T.; Lyons, M. Resilient dwellings or resilient people? Towards people-centred reconstruction. Environ. Hazards 2011, 10, 218-231. [CrossRef]

73. Von Meding, J.; Oyedele, L.; Bruen, J. Linking Organisational Competency to Project Success in Post-Disaster Reconstruction. Open House Int. 2014, 39, 9-18.

74. Koria, M. Managing for innovation in large and complex recovery programmes: Tsunami lessons from Sri. Lanka. Int. J. Proj. Manag. 2009, 27, 123-130. [CrossRef]

75. Zuo, K.; Potangaroa, R.; Wilkinson, S.; Rotimi, J.O. A project management prospective in achieving a sustainable supply chain for timber procurement in Banda Aceh, Indonesia. Int. J. Manag. Proj. Bus. 2009, 2, 386-400. [CrossRef]

76. Zuo, K.; Wilkinson, S. Supply chain and material procurement for post disaster construction: The Boxing Day Tsunami reconstruction experience in Aceh, Indonesia. In Proceedings from International Conference on Building Education and Research; University of Salford: Salford, UK, 2008.

77. Barenstein, J.D.; Pittet, D. Post-Disaster Housing Reconstruction: Current Trends and Sustainable Alternatives for Tsunami-Affected Communities in Coastal Tamil Nadu; Institute for Applied Sustainability to the Built Environment, University of Applied Sciences of Southern Switzerland: Canobbio, Switzerland, 2007.

78. Shaw, J.; Ahmed, I. Design and Delivery of Post-Disaster Housing Resettlement Programs; Case Studies from Sri Lanka and India Report; RMIT University: Melbourne, Australia, 2010.

79. Haigh, R.; Sutton, R. Strategies for the effective engagement of multi-national construction enterprises in post-disaster building and infrastructure projects. Int. J. Disaster Resil. Built Environ. 2012, 3, 270-282. [CrossRef]

80. Badan Rehabilitasi \& Rekonstruksi NAD-Nias. Aceh and Nias Two Years After the Tsunami: 2006 Progress Report; Badan Rehabilitasi \& Rekonstruksi NAD-Nias: Banda Aceh, Indonesia, 2006.

(c) 2018 by the authors. Licensee MDPI, Basel, Switzerland. This article is an open access article distributed under the terms and conditions of the Creative Commons Attribution (CC BY) license (http:/ / creativecommons.org/licenses/by/4.0/). 